\title{
Evidence for Association between the Brain-Derived Neurotrophic Factor Gene and Panic Disorder: A Novel Haplotype Analysis
}

\author{
Eun-Jin Han', Yong-Ku Kim ${ }^{1}$, Jung-A Hwang1, Seung-Hyun Kim², \\ Heon-Jeong Lee ${ }^{3}$, Ho-Kyoung Yoon ${ }^{1}$, and Kyeong-Sae $\mathrm{Na}^{4}$ \\ ${ }^{1}$ Department of Psychiatry, Korea University Ansan Hospital, Korea University College of Medicine, Ansan, Republic of Korea \\ ${ }^{2}$ Departmet of Psychiatry, Korea University Guro Hospital, Korea University College of Medicine, Seoul, Republic of Korea \\ ${ }^{3}$ Departmet of Psychiatry, Korea University Anam Hospital, Korea University College of Medicine, Seoul, Republic of Korea \\ ${ }^{4}$ Departmet of Psychiatry, Gacheon University Gil Hospital, School of Medicine, Incheon, Republic of Korea
}

Objective Panic disorder (PD) is a common psychiatric disorder with a complex etiology, and several studies have suggested that it has a genetic component. Brain-derived neurotrophic factor (BDNF) is the most abundant of the neurotrophins in the brain and is recognized for its important role in the survival, differentiation and growth of neurons. Several lines of research have suggested possible associations between the BDNF gene and PD. In this study, we investigated the BDNF 196G/A (rs6265), 11757G/C (rs16917204), and 270C/T (rs56164415) single nucleotide polymorphisms (SNPs) in order to determine an association with PD. We also identified the genetic sequence associations with $\mathrm{PD}$ via haplotype analysis.

Methods Participants in this study included 136 PD patients and 263 healthy controls. Male and female subjects were analyzed separately. The genotype and allele frequencies of the PD patients and controls were analyzed using $\chi^{2}$ statistics. Frequencies and haplotype reconstructions were calculated using the SNP analyzer 2.0.

Results We found no significant statistical differences in the genotype distributions or allele frequencies of the three tested polymorphisms between the PD and control groups. In addition, no differences were found between PD patients and the controls in either male or female subgroups. However, we found that, the frequency of the G-C haplotype for 196G/A and 11757G/C was significantly higher in PD patients than in the controls.

Conclusion Our result suggest that patients with the G-C haplotype for 196G/A and 11757G/C may be more susceptible to the development of PD. Further studies are needed to replicate the associations that we observed.

Psychiatry Investig 2015;12(1):112-117

Key Words Panic disorder, Brain-derived neurotrophic factor, Polymorphism.

\section{INTRODUCTION}

Panic disorder (PD) is an anxiety disorder characterized by recurrent, unexpected panic attacks, one or more of which is accompanied by worry about future attacks or their implications, or by a change in behavior related to the attacks.

Several studies have suggested a genetic component to PD.

Received: December 25, 2013 Revised: April 14, 2014

Accepted: April 28, 2014 Available online: October 1, 2014

$\triangle$ Correspondence: Yong-Ku Kim, MD, PhD

Department of Psychiatry, Korea University Ansan Hospital, Korea University College of Medicine, 123 Jeokgeum-ro, Danwon-gu, Ansan 152-703, Republic of Korea

Tel: +82-31-412-5140, Fax: +82-31-412-5144, E-mail: yongku@korea.ac.kr

(a) This is an Open Access article distributed under the terms of the Creative Commons Attribution Non-Commercial License (http://creativecommons.org/licenses/bync/3.0) which permits unrestricted non-commercial use, distribution, and reproduction in any medium, provided the original work is properly cited.
Family and twin studies indicate a genetic influence on PD, with heritability estimated at more than $40 \% .{ }^{1,2}$ Multiple genetic linkage studies have indicated that chromosomal regions 13q, 14q, 22q, 4q31-34, and most likely 9q31, are associated with PD. ${ }^{3}$ However, the genes involved and the specific roles of genetic variations in patients with PD remain unknown.

There has been a gradual emergence of research conceming into the underlying biological factors of PD. Brain-derived neurotrophic factor (BDNF) is a polypeptide encoded by a gene located on chromosome 11p13. ${ }^{4}$ BDNF is the most abundant of the neurotrophins in the brain, and is recognized for its important role in the survival, differentiation and growth of neurons. ${ }^{5-7} \mathrm{BDNF}$ is also crucially involved in activity-dependent neuronal plasticity. ${ }^{8}$ BDNF levels increased significantly after treatment in antidepressant responders, and BDNF may play 
a critical role in the pathophysiology of major depression and antidepressant treatment. ${ }^{9,10}$ Several lines of research have suggested associations between BDNF genes and PD. In an animal study, BDNF conditional mutant mice were found to be hyperactive after exposure to stressors and had higher levels of anxiety when evaluated in a light/dark exploration test. ${ }^{11}$ In another study, antidepressants were observed to suppress panic attacks, and chronic administration of antidepressants increased BDNF expression in the rat cerebral cortex. ${ }^{12}$ Several papers have reported that the 196G/A (rs6265) single nucleotide polymorphism (SNP) of the BDNF gene in the coding region of exon XIIIA is related to decreased hippocampal volume and hippocampus-medicated memory performance in humans. ${ }^{13-15}$ Based on these findings, it is reasonable to consider BDNF as a possible candidate gene involved in the pathophysiology of PD.

We hypothesized that the BDNF gene contributes to susceptibility to PD. The aim of the present study was to detect a possible association between three BDNF gene polymorphisms and PD. The three analyzed BDNF gene SNPs were: 196G/A (val66met, rs6265) in exon XIIIA, 11757G/C (rs16917204) in the 3' UTR of the BDNF gene, and 270C/T (rs56164415) in a non-coding region of exon $\mathrm{V}$.

Three previous studies have been published on the associations between PD and the 196G/A (rs6265) and, 270C/T (rs56164415) SNPs of the BDNF gene, ${ }^{16-18}$ though they detected no significant associations. However, no studies have been conducted on the association between $\mathrm{PD}$ and the BDNF gene through evaluation of the related haplotypes. In this study, we not only investigated the differences in genotype and allele frequencies between PD patients and controls, but also identified the genetic sequence association with $\mathrm{PD}$ via haplotype analysis. In previous studies, linkage disequilibrium analysis identified strong linkages between BDNF gene polymorphisms 196G/A (rs6265), 11757G/C (rs16917204), and 270C/ $\mathrm{T}$ (rs56164415). ${ }^{19,20}$ Furthermore, we aim to detect possible differences between male and female subgroups and examine the association of BDNF gene polymorphisms with PD in agoraphobia and non-agoraphobia subgroups. The identification of positive associations will help to establish the pathogenesis of $\mathrm{PD}$.

\section{METHODS}

\section{Subjects and assessments}

Study participants included 136 patients diagnosed with PD (79 males, 57 females). All patients met the Diagnostic and Statistial Manual of Mental Disorders, Fourth Edition (DSMIV) criteria for PD. Each patient was given a diagnostic assessment based on clinical interviews using the Structured Clinical
Interview for DSM-IV (SCID). ${ }^{21}$ Patients with comorbid mood disorder, any type of psychotic disorder (including schizophrenia), or other anxiety disorders were excluded. Concurrent agoraphobia was present in $70(74.5 \%)$ of the included patients.

The normal control group consisted of 263 randomly selected healthy individuals (138 males, 125 females) who visited Korea University Ansan Hospital for regular health screenings. Subjects were excluded if they had any self-reported personal or familial psychiatric history, or a history of psychotropic medication. All patients and control subjects were biologically unrelated native Koreans. Written informed consent was obtained from all subjects. The study protocol was approved by the Ethics Committee of Korea University.

\section{DNA analysis}

DNA was extracted from blood leukocytes using a commercial DNA extract kit (Wizard Genomic DNA Purification Kit, Promega, USA). In order to genotype the 196G/A (rs6265) $\mathrm{SNP}$ in the BDNF gene, polymerase chain reaction (PCR) was performed using the forward primer 5'-GAG GCT TGA CAT CAT TGG CT-3' and the reverse primer 5'-CGT GTA CAA GTC TGC GTC CT-3'. The amplification mixture contained $0.5 \mathrm{u} \mu \mathrm{L}$ of $100 \mathrm{ng} / \mu \mathrm{L}$ DNA, $2.5 \mu \mathrm{L}$ of $10 \mathrm{x}$ Taq buffer, $0.5 \mu \mathrm{L}$ of $10 \mathrm{mM}$ dNTP mixture, $1 \mu \mathrm{L}$ of primers, $19.375 \mu \mathrm{L}$ of distilled water, and $0.125 \mu \mathrm{L}$ of Taq DNA polymerase (SolGent, Korea). Samples were amplified using a thermocycler (Veriti 96-well thermal cycler, Applied Biosystems) for 35 cycles. After an initial $10 \mathrm{~min}$ at $95^{\circ} \mathrm{C}$, each cycle consisted of $30 \mathrm{sec}$ at $94^{\circ} \mathrm{C}$, $30 \mathrm{sec}$ at $62^{\circ} \mathrm{C}$, and $30 \mathrm{sec}$ at $72^{\circ} \mathrm{C}$. After a final $5 \mathrm{~min}$ at $72^{\circ} \mathrm{C}$, the reaction was terminated at $4^{\circ} \mathrm{C}$. The amplified DNA was digested with the restriction enzyme NIaIII (New England Biolabs), which cuts at the 196A site, and the product was electrophoresed on $3 \%$ agarose gels and stained with ethidium bromide. Homozygous genotypes were identified by the presence of 113bp bands (G/G), or bands of 75 and, 38 bp (A/A). The heterozygous genotype had 3 bands: 113,75 , and 38bp (C/G).

In order to genotype the 11757G/C (rs16917204) SNP in the BDNF gene, PCR was performed using the forward primer 5'-CCT CCT GCA GCC ATT AGT-3' and the reverse primer 5'-AAT ACA AGT AGG ACC CTA GC-3'. Amplification was performed using the same methods described for the BDNF 196G/A SNP. The amplified DNA was digested with the restriction enzyme AvaII (New England Biolabs). Homozygous genotypes were identified by the presence of 65,61 , and 44 bp bands (C/C), or bands of 105 and 65 (G/G). The heterozygous genotype $(\mathrm{C} / \mathrm{G})$ had all four bands.

In order to genotype the 270C/T (rs56164415) SNP in the BDNF gene, the reaction mixture consisted of $0.5 \mu \mathrm{L}$ of $100 \mathrm{ng} /$ $\mu \mathrm{L}$ DNA, $2.5 \mu \mathrm{L}$ of $10 \mathrm{x}$ Taq buffer, $0.5 \mu \mathrm{L}$ of $10 \mathrm{mM}$ dNTP 
mixture, $1 \mu \mathrm{L}$ of primers (forward primer: 5'-CAG AGG AGC CAG CCC GGT GCG-3', reverse primer 5'-CTC CTG CAC CAA GCC CCA TTC-3'), $9 \mu \mathrm{L}$ of Band Doctor, $10.375 \mu \mathrm{L}$ of distilled water, and $0.125 \mu \mathrm{L}$ of Taq DNA polymerase (SolGent, Korea). The amplified DNA was digested with the restriction enzyme Hinfl (New England Biolabs). Homozygous genotypes were identified by the presence of 127 and $78 \mathrm{bp}$ bands $(\mathrm{C} / \mathrm{C})$, or bands of 127 and 63 (T/T). The heterozygous genotype $(\mathrm{C} /$ T) had all three bands.

\section{Statistical analysis}

The presence of Hardy-Weinberg equilibrium was tested by using a $\chi^{2}$ test for goodness of fit. Differences in clinical variables were examined through t-tests. The genotype and allele frequencies of the PD patients and controls were analyzed using $\chi^{2}$ statistics and Fisher's exact test using SPSS version 12.0. Frequencies and haplotype reconstructions were calculated using the SNP analyzer 2.0 (http://snp.istech21.com/snpanalyzer/2.0/). The level of statistical significance was set at $\mathrm{p}<0.05$.

\section{RESULTS}

No significant difference was found in gender distribution between the PD patients (male:female=79:57) and healthy controls (male:female $=138: 125)\left(\chi^{2}=1.140, p=0.286\right)$. The mean age of PD patients was $40.6 \pm 9.6$ years and the mean age of control group participants was $31.2 \pm 8.4$ years. There was no significant difference in the mean age between the two groups $(\mathrm{t}=10.046, \mathrm{p}=0.052)$.

The distributions of the BDNF 196G/A (rs6265), 11757G/C (rs16917204), and 270C/T (rs56164415) polymorphisms in PD patients and controls were in agreement with the Hardy-
Weinberg equilibrium. The Hardy-Weinberg equilibria of the three candidate genes were as follows: BDNF 196G/A (rs6265) (PD, $\chi^{2}=0.6183, \mathrm{df}=1, \mathrm{p}=0.4317$; controls, $\chi^{2}=0.5107, \mathrm{df}=1, \mathrm{p}=$ 0.4748); BDNF 11757G/C (rs16917204) (PD, $\chi^{2}=2.9975, \mathrm{df}=1$, $\mathrm{p}=0.0834$; controls, $\left.\chi^{2}=2.2959, \mathrm{df}=1, \mathrm{p}=0.1297\right)$; and BDNF $270 \mathrm{C} / \mathrm{T}$ (rs56164415) (PD, $\chi^{2}=0.0169, \mathrm{df}=1, \mathrm{p}=0.8965$; controls, $\left.\chi^{2}=0.0010, \mathrm{df}=1, \mathrm{p}=0.9754\right)$. There were no significant statistical differences in the genotype distributions or the allele frequencies of the three tested polymorphisms between the PD and control groups (Table 1, 2, and 3).

In order to test the hypothesis that BDNF SNPs have a gender dependent effect on susceptibility to PD, the genotype and allele frequencies of male patients, female patients, and controls were compared. There were no differences between PD patients and controls in either the male or female subgroups. Furthermore, no significant association was demonstrated between PD patients and controls in agoraphobia subgroups (Table 1, 2, and 3).

Because the frequency of the T allele of the BDNF 270C/T (rs56164415) polymorphism was much lower than that of the $\mathrm{C}$ allele in both PD patients and the controls, only two SNPs [BDNF 196G/A (rs6265) and 11757G/C (rs16917204)] were analyzed for the calculation of haplotype frequencies. The calculation of haplotype frequencies in the PD group, as compared with the controls, revealed a statistically significant difference with regard to the G-C haplotype combinations [OR= 2.87; $\mathrm{p}=0.0002, \mathrm{p}^{*}=0.0009$ ( $\mathrm{p}^{*}$ is the $\mathrm{p}$ value obtained after the Bonferroni correction)] (Table 4 ). The patient groups showed a significantly higher frequency of the G-C haplotype (for 196G/A and 11757G/C) as compared with the controls. The frequency changes were $12.2 \%$ in patients and $4.3 \%$ in controls. After the Bonferroni correction, the findings regard-

Table 1. Genotype and allele frequencies of BDNF 196G/A (rs6265) in panic disorder (PD) patients and controls

\begin{tabular}{|c|c|c|c|c|c|c|c|c|c|}
\hline & \multicolumn{3}{|c|}{ Genotypes } & \multirow{2}{*}{$\chi^{2}$} & \multirow{2}{*}{$\mathrm{p}$} & \multicolumn{2}{|c|}{ Allele frequencies } & \multirow{2}{*}{$\chi^{2}$} & \multirow{2}{*}{$\mathrm{p}$} \\
\hline & $\mathrm{G} / \mathrm{G}$ & G/A & $\mathrm{A} / \mathrm{A}$ & & & G & $\mathrm{A}$ & & \\
\hline PD patients & 42 & 63 & 31 & 1.565 & 0.457 & 147 & 125 & 0.425 & 0.514 \\
\hline Controls & 81 & 135 & 47 & & & 297 & 229 & & \\
\hline Male PD patients & 25 & 35 & 19 & 0.479 & 0.787 & 85 & 73 & 0.485 & 0.486 \\
\hline Male controls & 48 & 62 & 28 & & & 158 & 118 & & \\
\hline Female PD patients & 17 & 28 & 12 & 1.562 & 0.458 & 62 & 52 & 0.047 & 0.829 \\
\hline Female controls & 33 & 73 & 19 & & & 139 & 111 & & \\
\hline Male controls & 48 & 62 & 28 & 4.767 & 0.092 & 158 & 118 & 0.145 & 0.704 \\
\hline Female controls & 33 & 73 & 19 & & & 139 & 111 & & \\
\hline PD with agoraphobia & 26 & 39 & 23 & 2.947 & 0.229 & 91 & 85 & 1.208 & 0.272 \\
\hline Controls & 81 & 135 & 47 & & & 297 & 229 & & \\
\hline PD without agoraphobia & 16 & 24 & 8 & 0.131 & 0.937 & 56 & 40 & 0.116 & 0.734 \\
\hline Controls & 81 & 135 & 47 & & & 297 & 229 & & \\
\hline
\end{tabular}

BDNF: brain-derived neurotrophic factor 
ing the G-C haplotype remained significant.

\section{DISCUSSION}

PD is a common psychiatric disorder with a complex etiology that likely involves multiple genes in addition to nongenetic influences. ${ }^{22-27}$ Many previous studies have identified associations between BDNF polymorphisms and psychiatric disorders. Associations have been found between the BDNF 196G/ A (rs6265) polymorphism and chronic depression, ${ }^{28}$ treatment response in patients with major depression, ${ }^{29}$ and Alzheimer's disease, ${ }^{30,31}$ although findings have not always been consistent. Additionally, the BDNF 11757G/C (rs16917204) polymorphism may be associated with Alzheimer's disease $\mathrm{e}^{19,32,33}$ and schizophrenia. ${ }^{34}$ The last polymorphisms located in the 5'-untranslated lesion (UTR) BDNF 270C/T (rs56164415) are associated with Alzheimer's disease, ${ }^{19}$ anorexia nervosa, ${ }^{35}$ and treatment response in schizophrenia. ${ }^{36}$

This study found no genotype or allele distribution differences between PD patients and controls. These results are consistent with the results of previous studies. For example, Lam et al. ${ }^{16}$ reported finding no differences in BDNF gene 196G/ A (rs6265) polymorphisms between patient and control groups and no association between the polymorphism and PD with agoraphobia in a Chinese population. Shimizu et al. ${ }^{18}$ similarly reported finding no significant differences in the frequencies of the genotypes or alleles of two BDNF SNPs [196G/A (rs6265), $270 \mathrm{C} / \mathrm{T}$ (rs56164415)] between patients and controls in a Japa-

Table 2. Genotype and allele frequencies of BDNF 11757G/C (rs16917204) in panic disorder (PD) patients and controls

\begin{tabular}{|c|c|c|c|c|c|c|c|c|c|}
\hline & \multicolumn{3}{|c|}{ Genotypes } & \multirow{2}{*}{$\chi^{2}$} & \multirow{2}{*}{$\mathrm{p}$} & \multicolumn{2}{|c|}{ Allele frequencies } & \multirow{2}{*}{$\chi^{2}$} & \multirow{2}{*}{$\mathrm{p}$} \\
\hline & G/G & $\mathrm{G} / \mathrm{C}$ & $\mathrm{C} / \mathrm{C}$ & & & G & $\mathrm{C}$ & & \\
\hline PD patients & 48 & 57 & 31 & 1.445 & 0.486 & 153 & 119 & 1.312 & 0.252 \\
\hline Controls & 102 & 114 & 47 & & & 318 & 208 & & \\
\hline Male PD patients & 29 & 32 & 18 & 0.807 & 0.668 & 90 & 68 & 0.898 & 0.343 \\
\hline Male controls & 59 & 52 & 27 & & & 170 & 106 & & \\
\hline Female PD patients & 19 & 25 & 13 & 1.283 & 0.526 & 63 & 51 & 0.498 & 0.48 \\
\hline Female controls & 43 & 62 & 20 & & & 148 & 102 & & \\
\hline Male controls & 59 & 52 & 27 & 3.796 & 0.15 & 170 & 106 & 0.315 & 0.575 \\
\hline Female controls & 43 & 62 & 20 & & & 148 & 102 & & \\
\hline PD with agoraphobia & 26 & 41 & 21 & 2.923 & 0.232 & 93 & 83 & 3.151 & 0.076 \\
\hline Controls & 102 & 114 & 47 & & & 318 & 208 & & \\
\hline PD without agoraphobia & 22 & 16 & 10 & 1.674 & 0.433 & 60 & 36 & 0.142 & 0.706 \\
\hline Controls & 102 & 114 & 47 & & & 318 & 208 & & \\
\hline
\end{tabular}

BDNF: brain-derived neurotrophic factor

Table 3. Genotype and allele frequencies of BDNF 270C/T (rs56164415) in panic disorder (PD) patients and controls

\begin{tabular}{|c|c|c|c|c|c|c|c|c|c|}
\hline & \multicolumn{3}{|c|}{ Genotypes } & \multirow{2}{*}{$\chi^{2}$} & \multirow{2}{*}{$\mathrm{p}$} & \multicolumn{2}{|c|}{ Allele frequencies } & \multirow{2}{*}{$\chi^{2}$} & \multirow{2}{*}{$\mathrm{p}$} \\
\hline & $\mathrm{C} / \mathrm{C}$ & $\mathrm{C} / \mathrm{T}$ & $\mathrm{T} / \mathrm{T}$ & & & $\mathrm{C}$ & $\mathrm{T}$ & & \\
\hline PD patients & 133 & 3 & 0 & 3.011 & 0.083 & 269 & 3 & 2.995 & 0.084 \\
\hline Controls & 262 & 1 & 0 & & & 525 & 1 & & \\
\hline Male PD patients & 78 & 1 & 0 & 1.755 & 0.185 & 157 & 1 & 1.751 & 0.186 \\
\hline Male controls & 138 & 0 & 0 & & & 276 & 0 & & \\
\hline Female PD patients & 55 & 2 & 0 & 1.772 & 0.183 & 112 & 2 & 1.757 & 0.185 \\
\hline Female controls & 124 & 1 & 0 & & & 249 & 1 & & \\
\hline Male controls & 138 & 0 & 0 & 1.108 & 0.292 & 276 & 0 & 1.106 & 0.293 \\
\hline Female controls & 124 & 1 & 0 & & & 249 & 1 & & \\
\hline PD with agoraphobia & 86 & 2 & 0 & 2.787 & 0.095 & 174 & 2 & 2.775 & 0.096 \\
\hline Controls & 262 & 1 & 0 & & & 525 & 1 & & \\
\hline PD without agoraphobia & 47 & 1 & 0 & 1.843 & 0.175 & 95 & 1 & 1.837 & 0.175 \\
\hline Controls & 262 & 1 & 0 & & & 525 & 1 & & \\
\hline
\end{tabular}

BDNF: brain-derived neurotrophic factor 
Table 4. Haplotype analysis for BDNF SNPs in panic disorder patients and controls

\begin{tabular}{|c|c|c|c|c|c|c|c|}
\hline \multicolumn{2}{|c|}{ SNP } & \multicolumn{2}{|c|}{ Frequency (\%) } & \multirow[b]{2}{*}{ OR } & \multirow[b]{2}{*}{$95 \% \mathrm{CI}$} & \multirow[b]{2}{*}{$\mathrm{p}$-value } & \multirow[b]{2}{*}{ p-value* } \\
\hline -196G/A (rs6265) & $\begin{array}{c}-11757 \mathrm{G} / \mathrm{C} \\
(\mathrm{rs} 16917204)\end{array}$ & Patients & Controls & & & & \\
\hline G & G & 41.82 & 52.11 & 0.694 & $0.157-0.932$ & 0.015 & 0.06 \\
\hline A & $\mathrm{C}$ & 31.53 & 35.2 & 0.896 & $0.658-1.221$ & 0.488 & $(-)$ \\
\hline A & G & 14.43 & 8.34 & 1.702 & $1.059-2.736$ & 0.027 & 0.107 \\
\hline G & $\mathrm{C}$ & 12.22 & 4.35 & 2.87 & $1.604-5.136$ & 0.0002 & 0.0009 \\
\hline
\end{tabular}

*p-value after Bonferroni correction. BDNF: brain-derived neurotrophic factor

nese population. Otowa et al. ${ }^{17}$ subsequently reported no significant association between three BDNF SNPs, including BDNF 196G/A (rs6265), and PD in a Japanese population.

$\mathrm{PD}$ is approximately twice as common in women as in men, with a $5 \%$ lifetime prevalence among women versus $2 \%$ among men. ${ }^{37}$ A study including analyses stratified by gender revealed that female patients had lower levels of BDNF than female controls, and this result was stronger in female patients with anxiety disorders. ${ }^{38}$ Therefore, we subdivided our PD and healthy control groups by gender. However, the hypothesis that BDNF SNPs have a gender-dependent effect on susceptibility to PD was not supported by our analysis. Furthermore, no association was observed between polymorphisms of BDNF genes and PD with agoraphobia.

Because the three BDNF polymorphisms analyzed in our study are linked, we calculated the haplotype frequencies, finding that the frequency of the G-C haplotype (for 196G/A and $11757 \mathrm{G} / \mathrm{C}$ ) is significantly higher in $\mathrm{PD}$ patients than in controls. Our results suggest that patients with the G-C haplotype (for 196G/A and 11757G/C) may be more susceptible to the development of PD.

There are some limitations to this study. First, the sample size was not sufficient to detect associations within the subgroups of PD. Our results showed that the frequency of the T allele portion of the BDNF 270C/T (rs56164415) polymorphism was much lower than that of the $\mathrm{C}$ allele portion in both $\mathrm{PD}$ patients and controls. This result is consistent with previous research in Japanese and Caucasian samples, ${ }^{18,39-42}$ suggesting that such allele distributions might not have ethnic variability. The low frequency of the $\mathrm{T}$ allele may make the results prone to false positive errors, especially when small samples are analyzed. It is meaningful that our sample size is larger than those used in previous studies (Lam et al. ${ }^{16}: 103$ patients, 180 controls; Shimizu et al. ${ }^{18}$ : 109 patients, 178 controls). In our haplotype analysis, the sample sizes of the GC allele subgroups ( $12 \%$ of patients, $4 \%$ of controls) were relatively small, and our hypothesis might be confirmed in a study using a larger sample. Second, our population consisted exclusively of Korean subjects, without ethnic diversity. Previous studies on genetic associations in $\mathrm{PD}$ also examined only Asian groups; there- fore, research investigating diverse ethnic groups is needed. Third, we investigated only BDNF SNPs. In future research, association studies with multiple genes are needed to identify possible genetic interactions and the pathogenesis of PD. Further, clinical research should examine the possible relationships between genetic variations of BDNF and panic symptom severity or antidepressant treatment response. Moreover, studies identifying possible associations between the BDNF polymorphism and BDNF levels would be helpful in understanding the pathophysiology of PD.

$\mathrm{PD}$ is a complex and heterogeneous psychiatric condition. In addition to genetic factors, neurobiological and psychosocial factors may be involved in pathogenesis of $\mathrm{PD}$, and these factors may interact with each other. An understanding of this heterogeneity will be facilitated by the continued development and application of genetic, neurobiological, neuroimaging, and cognitive-behavioral approaches, which can refine PD phenotypes and elucidate the genotypes associated with this disorder.

\section{REFERENCES}

1. Hettema JM, Neale MC, Kendler KS. A review and meta-analysis of the genetic epidemiology of anxiety disorders. Am J Psychiatry 2001; 158:1568-1578.

2. Kessler R. Review: major anxiety disorders all have substantive familial aggregation. Evid Based Ment Health 2002;5:92.

3. Maron E, Hettema JM, Shlik J. Advances in molecular genetics of panic disorder. Mol Psychiatry 2010;15:681-701.

4. Maisonpierre PC, Le Beau MM, Espinosa R 3rd, Ip NY, Belluscio L, de la Monte SM, et al. Human and rat brain-derived neurotrophic factor and neurotrophin-3: gene structures, distributions, and chromosomal localizations. Genomics 1991;10:558-568.

5. Huang EJ, Reichardt LF. Neurotrophins: roles in neuronal development and function. Annu Rev Neurosci 2001;24:677-736.

6. Schinder AF, Poo M. The neurotrophin hypothesis for synaptic plasticity. Trends Neurosci 2000;23:639-645.

7. Ashe PC, Berry MD, Boulton AA. Schizophrenia, a neurodegenerative disorder with neurodevelopmental antecedents. Prog Neuropsychopharmacol Biol Psychiatry 2001;25:691-707.

8. Gartner A, Staiger V. Neurotrophin secretion from hippocampal neurons evoked by long-term-potentiation-inducing electrical stimulation patterns. Proc Natl Acad Sci U S A 2002;99:6386-6391.

9. Lee HY, Kim YK. Plasma brain-derived neurotrophic factor as a peripheral marker for the action mechanism of antidepressants. Neuropsychobiology 2008;57:194-199.

10. Lee BH, Kim YK. The roles of BDNF in the pathophysiology of major 
depression and in antidepressant treatment. Psychiatry Investig 2010;7: 231-235.

11. Rios M, Fan G, Fekete C, Kelly J, Bates B, Kuehn R, et al. Conditional deletion of brain-derived neurotrophic factor in the postnatal brain leads to obesity and hyperactivity. Mol Endocrinol 2001;15:1748-1757.

12. Nibuya M, Morinobu S, Duman RS. Regulation of BDNF and trkB mRNA in rat brain by chronic electroconvulsive seizure and antidepressant drug treatments. J Neurosci 1995;15:7539-7547.

13. Egan MF, Kojima M, Callicott JH, Goldberg TE, Kolachana BS, Bertolino A, et al. The BDNF val66met polymorphism affects activity-dependent secretion of BDNF and human memory and hippocampal function. Cell 2003;112:257-269.

14. Hariri AR, Goldberg TE, Mattay VS, Kolachana BS, Callicott JH, Egan $\mathrm{MF}$, et al. Brain-derived neurotrophic factor val66met polymorphism affects human memory-related hippocampal activity and predicts memory performance. J Neurosci 2003;23:6690-6694.

15. Szeszko PR, Lipsky R, Mentschel C, Robinson D, Gunduz-Bruce H, Sevy S, et al. Brain-derived neurotrophic factor val66met polymorphism and volume of the hippocampal formation. Mol Psychiatry 2005;10: 631-636.

16. Lam P, Cheng CY, Hong CJ, Tsai SJ. Association study of a brain-derived neurotrophic factor (Val66Met) genetic polymorphism and panic disorder. Neuropsychobiology 2004;49:178-181.

17. Otowa T, Shimada T, Kawamura Y, Liu X, Inoue K, Sugaya N, et al. No association between the brain-derived neurotrophic factor gene and panic disorder in Japanese population. J Hum Genet 2009;54:437-439.

18. Shimizu E, Hashimoto K, Koizumi H, Kobayashi K, Itoh K, Mitsumori $\mathrm{M}$, et al. No association of the brain-derived neurotrophic factor (BDNF) gene polymorphisms with panic disorder. Prog Neuropsychopharmacol Biol Psychiatry 2005;29:708-712.

19. Boiocchi C, Maggioli E, Zorzetto M, Sinforiani E, Cereda C, Ricevuti $\mathrm{G}$, et al. Brain-derived neurotrophic factor gene variants and Alzheimer disease: an association study in an Alzheimer disease Italian population. Rejuvenation Res 2013;16:57-66.

20. Jonsson EG, Edman-Ahlbom B, Sillen A, Gunnar A, Kulle B, Frigessi A, et al. Brain-derived neurotrophic factor gene (BDNF) variants and schizophrenia: an association study. Prog Neuropsychopharmacol Biol Psychiatry 2006;30:924-933.

21. First M, Spitzer R, Gibbon M. Structured Clinical Interview for DSM IV Axis I Disorder Patient Edition. New York: New York State Psychiatric Institute; 1998.

22. Ishitobi Y, Nakayama S, Yamaguchi K, Kanehisa M, Higuma H, Maruyama Y, et al. Association of CRHR1 and CRHR2 with major depressive disorder and panic disorder in a Japanese population. Am J Med Genet B Neuropsychiatr Genet 2012;159B:429-436.

23. Kim YK, Lee HJ, Yang JC, Hwang JA, Yoon HK. A tryptophan hydroxylase 2 gene polymorphism is associated with panic disorder. Behav Genet 2009;39:170-175.

24. Koido K, Eller T, Kingo K, Koks S, Traks T, Shlik J, et al. Interleukin 10 family gene polymorphisms are not associated with major depressive disorder and panic disorder phenotypes. J Psychiatr Res 2010;44:275277.

25. Unschuld PG, Ising M, Erhardt A, Lucae S, Kloiber S, Kohli M, et al. Polymorphisms in the serotonin receptor gene HTR2A are associated with quantitative traits in panic disorder. Am J Med Genet B Neuropsychiatr Genet 2007;144B:424-429.

26. Ising M, Hohne N, Siebertz A, Parchmann AM, Erhardt A, Keck M.
Stress response regulation in panic disorder. Curr Pharm Des 2012;18: 5675-5684.

27. Starcevic V, Sammut P, Berle D, Hannan A, Milicevic D, Moses K, et al. Can levels of a general anxiety-prone cognitive style distinguish between various anxiety disorders? Compr Psychiatry 2012;53:427-433.

28. Lee Y, Lim SW, Kim SY, Chung JW, Kim J, Myung W, et al. Association between the BDNF Val66Met polymorphism and chronicity of depression. Psychiatry Investig 2013;10:56-61.

29. Kocabas NA, Antonijevic I, Faghel C, Forray C, Kasper S, Lecrubier Y, et al. Brain-derived neurotrophic factor gene polymorphisms: influence on treatment response phenotypes of major depressive disorder. Int Clin Psychopharmacol 2011;26:1-10.

30. Desai P, Nebes R, DeKosky ST, Kamboh MI. Investigation of the effect of brain-derived neurotrophic factor (BDNF) polymorphisms on the risk of late-onset Alzheimer's disease $(\mathrm{AD})$ and quantitative measures of AD progression. Neurosci Lett 2005;379:229-234.

31. Ventriglia M, Bocchio Chiavetto L, Benussi L, Binetti G, Zanetti O, Riva MA, et al. Association between the BDNF 196 A/G polymorphism and sporadic Alzheimer's disease. Mol Psychiatry 2002;7:136-137.

32. Borroni B, Grassi M, Archetti S, Costanzi C, Bianchi M, Caimi L, et al. BDNF genetic variations increase the risk of Alzheimer's disease-related depression. J Alzheimers Dis 2009;18:867-875.

33. Zhang L, Fang Y, Zeng Z, Lian Y, Wei J, Zhu H, et al. BDNF gene polymorphisms are associated with Alzheimer's disease-related depression and antidepressant response. J Alzheimers Dis 2011;26:523-530.

34. Varnas K, Lawyer G, Jonsson EG, Kulle B, Nesvag R, Hall H, et al. Brain-derived neurotrophic factor polymorphisms and frontal cortex morphology in schizophrenia. Psychiatr Genet 2008;18:177-183.

35. Rybakowski F, Dmitrzak-Weglarz M, Szczepankiewicz A, Skibinska M, Slopien A, Rajewski A, et al. Brain derived neurotrophic factor gene Val66Met and -270C/T polymorphisms and personality traits predisposing to anorexia nervosa. Neuro Endocrinol Lett 2007;28:153-158.

36. Xu M, Li S, Xing Q, Gao R, Feng G, Lin Z, et al. Genetic variants in the BDNF gene and therapeutic response to risperidone in schizophrenia patients: a pharmacogenetic study. Eur J Hum Genet 2010;18:707-712.

37. Kessler RC, McGonagle KA, Zhao S, Nelson CB, Hughes M, Eshleman $\mathrm{S}$, et al. Lifetime and 12-month prevalence of DSM-III-R psychiatric disorders in the United States. Results from the National Comorbidity Survey. Arch Gen Psychiatry 1994;51:8-19.

38. Molendijk ML, Bus BA, Spinhoven P, Penninx BW, Prickaerts J, Oude Voshaar RC, et al. Gender specific associations of serum levels of brainderived neurotrophic factor in anxiety. World J Biol Psychiatry 2012;13: 535-543.

39. Anttila S, Illi A, Kampman O, Mattila KM, Lehtimaki T, Leinonen E. Lack of association between two polymorphisms of brain-derived neurotrophic factor and response to typical neuroleptics. J Neural Transm 2005;112:885-890.

40. Nanko S, Kunugi H, Hirasawa H, Kato N, Nabika T, Kobayashi S. Brainderived neurotrophic factor gene and schizophrenia: polymorphism screening and association analysis. Schizophr Res 2003;62:281-283.

41. Szekeres G, Juhasz A, Rimanoczy A, Keri S, Janka Z. The C270T polymorphism of the brain-derived neurotrophic factor gene is associated with schizophrenia. Schizophr Res 2003;65:15-18.

42. Chen L, Lawlor DA, Lewis SJ, Yuan W, Abdollahi MR, Timpson NJ, et al. Genetic association study of BDNF in depression: finding from two cohort studies and a meta-analysis. Am J Med Genet B Neuropsychiatr Genet 2008;147B:814-821. 